\title{
The Ecology of Human Beings (Homo sapiens) and Habitat Design
}

\author{
Steven N. Handel
}

[Much attention has been given to various plant and animal species of special interest central to habitat restoration. However, the animal with the greatest impact on many sites, and the one whose activities will be closely aligned with the future success of the restored habitats is our species, the human. What human ecological needs in design guidelines are needed to express our strong links with the rest of the living world? Our behavior so mirrors the constellation of biotic needs more usually discussed in the realm of wildlife science. By restorationists and park designers considering us in the same analytical style as for our vertebrate neighbors, our commonalities may better come into focus. Restored areas may be more highly valued.]

Physical Description: Widely varying appearances are typical among humans, in size, coloration, and proportions (Mickey Rooney vs. Shaquille O’Neal, for example). This variety adds much interest to the study of human populations. Humans start life at about 7 pounds $(3 \mathrm{~kg}$ ) and reach full size after about 20 years. Additional weight can be gained throughout life (see "Diet"). Adult human males are on average $68^{\prime \prime}(175 \mathrm{~cm})$ tall in North America, women at $64^{\prime \prime}(162 \mathrm{~cm})$, with many people somewhat larger or smaller. Individuals at the extreme sizes fill special niches in human groups, such as jockeys or bouncers. However, humans of any size can be found in almost any activity, evidence of their generalist abilities, and the equitability of talents across many groups.

Humans vary broadly in skin color, from white to black, although most are pink to brown in tone. This color can be modified by exposure to sun, tanning salons, or by applied skin decorations (as is increasing in frequency among younger humans) ("Grateful Dead," "Mom," and spider-webby thingies commonly seen). Similarly, human hair varies from white or black, with increasing proportions recently being seen in the purple, red, green, or frosted tones. These colors change with age and by purposeful manipulation. Length of head hair varies from 2 -foot $(70 \mathrm{~cm})$ long to cut near to the scalp. Some humans

Ecological Restoration Vol. 34, No. 2, 2016

ISSN 1522-4740 E-ISSN 1543-4079

(O2016 by the Board of Regents of the University of Wisconsin System. purposely remove all hair from scalp, legs, or face. Others manipulate hair into almost sculptural shapes and braiding, aiding in identification of individuals within a group. This is analogous to studying tail fin markings in humpback whales.

Humans cover and decorate their bodies. Clothes, useful for protection against extreme climate conditions, are prepared from many materials (plant fibers such as cotton and flax, plastics, skins, hair, fiberglass, recycled soda bottles) and, curiously, are made in every color of the rainbow. The colors used change from time to time for no functional reason (this is called "fashion"), and must be attributed to complex social interactions. In some populations, there is particular attention to different clothes being chosen each morning. In mild climates, these clothes often do not cover extremities. Many clothes display the clan or niche identity of the wearer (Hell's Angels, Notre Dame, Old Navy, Life is Good, Old Guys Rule, Rather Be Fishing, Go Steelers, and so on).

It is rare to see a very large group of humans whose members are all similar in appearance. Most typically, congregations will be extremely diverse physically. The groups of humans expected in accessible restored areas should offer a kaleidoscope of colors and a huge diversity of human shapes, adding much to the experience of visiting the area. Restoration monitoring in many urbanized habitats regularly reveals an encyclopedia of the scope of human diversity.

Social Behavior: Humans are social animals, and most activities involve other individuals and rely on others. Indeed, the decision to even have a restored landscape is usually a social behavior. Humans in the landscape are typically found in small groups. Sometimes the groups are of mixed ages, with adults leading or dragging juveniles to different activities, as part of the maturation process toward independent living. These "nuclear families" are seen predominantly on weekends, when age-specific activities (schooling, corporate work, Weight Watchers, kick-boxing lessons) are not happening, and the family group coalesces.

More frequently, one often sees groups of same-aged humans wandering in the landscape. Groups of young are 
noisy, active, and running seemingly aimlessly from place to place. Male and female groups of young tend to stay separate, as they are contemptuous of the other sex ("Yuck, boys!", "Yuck, girls!"). This ethological pattern fades with age. Adolescent groups are quite different. Also noisy, with sounds that can defy common understanding ("hey dude," "sweeeet," "duh," "later"), these groups are notable for their garish, even bizarre, body coverings. Curiously, even new body coverings are obtained worn looking and torn. These groups stay apart from other age classes, apparently uncomfortable when in the presence of adult groups or with juveniles, age classes with which they do not wish to be associated. Adult groups are quieter and smaller, usually of mixed sexes. They can be discriminated at a distance by their relatively slow gait, soft, murmuring sounds, and furrowed brows. A selection of different trail systems of varying widths and surfacing is needed in landscape design to accommodate these various groupings.

Post-reproductive, older groups of humans are common in the landscape, and have distinct behaviors. Often groups of only older females are seen together, as their life-span is longer than males. Sometimes older individuals are found amidst groups of very young humans, and show protective behavior, teaching group skills. The older groups generally lack the colorful hair displays of young age classes, walk only short distances, and are wary. Being experienced in traversing natural habitats and knowing their dangers, older humans sometimes approach younger individuals offering help. Often, the younger ones completely ignore the advice given.

Large groups containing all age classes are found together only during certain uncommon social rituals, such as "craft fairs," "family reunions," and "graduation." Some areas of the landscape may be made available for these large seasonal migrations, which can be quite colorful and would attract members of the human species that exhibit special behaviors such as photography or dish-to-pass luncheons.

Consequently, design criteria for restored areas must particularly include many small landscape areas directed towards the behavior of each age class group, understanding that the habitat must be a mosaic of these microhabitats that taken together are appropriate for this species as a whole. Any larger areas planned for cultural ecological services (art, music, tai chi) also need to keep this agespecific separation of preferences in mind, so that the suite of habitats attract and console humans of each age class. Universality of use can only be achieved by a balkanization of habitat types.

Reproductive behavior: In humans, this is quite unusual, even within the primate family. Courtship behavior commences during the second decade of life and continues through all later age classes. Individual mating displays include special clothes, changes in hair color (analogous to courtship feather displays in birds), skin color change and ornaments (as in many reptiles), vocal cues (coo-ing, singing, whistling, long stretches of vapid verbalizing on the telephone), and other attention-getting aids, including displays of possessions, analogous to bower bird mating arenas in the south Pacific. Courtship behavior is exhibited throughout the year, not at specific seasonal windows, though a slight increase can be noted in the spring, when baseball season commences. Courtship behavior can occur at any time of day, with more pair bonding elicited at dusk. Curiously, early stages of this behavior can occur in congregations of humans (libraries, checkout lines, microbreweries), but later stages of displays are typically in private, isolated settings. Sometimes courtship commences using solely electronic media, with all physical proximity and experience completing lacking. This is unique among primates, but comparable to long-distance courtship communication by pheromone-emitting insects.

The frequent occurrence of courtship behavior, among so many age classes, at so many times, and at a mix of microhabitats from open to secluded areas present the landscape design team with serious complexities. The near universal need for courtship in this species suggests that romantic locales, from large to small scale, be distributed throughout the landscape. However, these needs can be meshed with other habitat functions, such as pollination meadows, sidelines of soccer fields, waiting lines at food venues, oviposition microsites near streams, park benches within interior woodlands, or brightly colored frugivorous bird foraging displays. Humans search out these areas, a behavior called "cruising".

Courtship behavior is typically accompanied by extreme emotional outbursts, ranging from giddy laughter to sobbing tears. Consequently, pairs involved in courtship displays should only be approached with the greatest of caution. Courtship arenas designed to be distant from habitats designed for other less neurologically charged emotional uses would be most effective.

Habitat use: Humans are catholic in their use of habitats. Some prefer sun, others shade. Some like wide open spaces ("don't fence me in" is a culturally historic expression), others search for intimate, quiet microhabitats ("getting away from it all"). Happily, many sizable restoration projects allow the designers to accommodate both spatial needs. Humans go everywhere; it should not be assumed that any areas will not feel their presence and effects. Management of the landscape should assume that human use and overuse will be a continual issue. Humans do not like very dark areas, except during sleeping times, which should most frequently occur off-site. Ecologically sensitive lighting plans must be considered for all trails and public use areas. The fear of dark, driven by habitual wariness of predators, drives many humans to over-illuminated walkways. This is neither necessary nor sustainable. Efforts to more properly use low light levels and to limit upwards 
facing lights (the "dark sky" initiatives) are increasing. Plans for having areas that are lighted by activation of movement sensors are strategic decisions to satisfy both non-human preference for dark spaces and human avoidance of dark. With training and positive reinforcements, humans will accept these lower lighting conditions.

Humans also search for cooling, aquatic habitats during hot periods. Waterways and ponding areas for swimming and other water play should serve this need. It is amusing to watch humans cavorting in water, with their droll antics and colorful, though minute, skin coverings ("bikinis"). Humans require air, however, and will not compete for submarine habitat with our fish or amphibian communities. Consequently allowing humans into the water will not compromise many aquatic biodiversity goals.

The numbers and high activity levels of humans will heavily impact the ecosystem functions in many landscapes. Use of space, trampling of soil, mindless or purposeful destruction of plantings, emissions of wastes, and heavy use of water will change the inflows and outflows of hydrological, geological, and atmospheric materials. The design of sustainable landscapes must be advanced with full appreciation that these ecosystem flows are controlled, in large part, by the human species, despite the hundreds of other sympatric species present. The traditional separation of the human world and the natural world is a conceit, which must never cloud the decisions of the habitat management team.

Diet breadth: Omnivorous, humans have diets that are notable for their variety, complexity, volume, and role in social interactions as well as in metabolic functioning. Additionally, the wide variety of human appearances is matched by a wide variety of eating styles, seemingly by preference, not physiological requirement.

Human diet consists of hundreds of items, ranging across many plant parts (stems, fruits, roots, tubers, flowers, seeds, leaves, saps, and exudates) and across many plant groups (algae, gymnosperms, and both groups of angiosperms, the monocotyledons and dicotyledons), and fungi. For example, included in these wide grouping are bananas, truffles, yams, cactus pads, rambutans, kumquats, sushi wrappers, naval oranges, eggplant, nectarines, Yukon gold potatoes, mother hubbard squash, and boysenberries. The full list is beyond the scope of this journal.

Of special significance is the seed production of several grasses (wheat, rye, rice, barley, corn) which form the majority of foodstuffs for people around the world (the "staples"). These grass seeds are often highly modified before eating ("cheerios," "freetos," "rice crispies," "poptarts," nachos, and so on). It is amusing to observe human groups devour these items, many of which make peculiar sounds when being eaten (crunch, snap, crackle, etc.).

Parallel to plant foods, humans often eat animal parts (predominately muscle, but also organs and renderings and fluids extracted by heating). Many animals are devoured, usually mammals, birds, fish, and some mollusks. Humans encourage the local reproduction of many of these animals ("ranching") to increase their supply for consumption. Occasionally, some humans eat reptiles (turtle soup), amphibians (frogs' legs), and insects (witchetty grubs), but this is quite uncommon in North America. These have not reached the level of a fast food option ("I'll have a number 5 , the gecko combo."). Use of these taxa is not encouraged by ecological advocates as these animals have other important ecological functions.

Eating behavior: Both plant and animal food items are notable for the complex preparation that humans perform before eating. Some preparations are so intricate that hours are needed, which could be more usefully spent on other human activities such as a vocation, child rearing, and observing athletic contests on electronic media. Preparation modes include chopping, dicing, grating, peeling, mashing, filleting, stuffing, pureeing, drying, and aging. After this manipulation, foods are not simply eaten in the raw state (though this is more common for fruits and thin slices of tuna), as by other mid-sized mammals. Often foods are boiled, sautéed, roasted, barbequed, poached, fried, steamed, frozen (!), stewed, or braised. Consequently, spaces are needed that are reserved for extensive food preparations, though some of this could be off-site, with prepared foods transported in. Many humans carry their foods with them, to facilitate eating at any time. Specially fabricated containers are made to ease this transport of foods (picnic baskets, backpacks, ziplock bags, cargo pants, Tupperware).

Any grouping of humans will be seen eating these items, seemingly at any time of day. Some groups even have ritualized very late eating, the "midnight snack," in complete disregard for normal diurnal living cycles. Other groups continually interrupt other behavior patterns just to eat ("coffee break," "snack," "happy hour," "the munchies"). The primacy of eating over other potential behaviors seems a general occurrence, and social space must be accommodated for this in the landscape.

It has been noted by many investigators that humans often eat more than is necessary to support their daily metabolic needs. Consequently, they store energy ("get fat"). In many populations, this phenomenon has become common, negatively effecting longevity and the ability to perform other normal human behaviors ("obesity related diseases"). Designers should be aware of this tendency, and supply alternative activities that challenge the ability of humans to so badly manage their diet. It should be noted that the interest of humans in high fat foods and continual feeding sessions is probably deeply rooted in the evolutionary history of this species. On the ancestral plains of Africa, selection favored the behavior of searching out fatty items and exploiting any food item, whenever found 
in that inhospitable and dangerous habitat; modifying a behavior that is so primitive to humans will require special attention to alternative programming, to break a long-held pattern, a "social habit."

Threats: Being mammals with few natural physical defenses such as great strength, large canines or claws, speed, or escape behavior as in other vertebrate groups (flight or ability to swim beneath the water surface), the evolutionary history of humans stressed wariness, caution, and social aggregations when threats are perceived. "Strength in numbers" is an oft' verbalized expression of this behavior. In fact, many current habitats contain very few physical threats from the natural world. Most true threats to humans are associated with their own actions: misuse of vehicular machines, actions of individuals who challenge social mores to garner possessions or social power, and illnesses from life styles that have strayed far from ancestral biological needs ("couch potatoes", "loners," and, of course, see the "Diet" section again).

Habitat design must be cognizant of this deeply-seated wariness, and include open areas, well-lit paths at dusk, and the regular appearance of humans whose special niche is group protection, the uniformed services and professional staff. The other initiative that must be developed to parry the instinct of wariness is a carefully-conceived education program, to teach humans new to natural settings that few environmental threats are actually present. Most insects and small mammals, for example, can be objects of wonder, not elements from which to flee. Successful programming towards this goal will also lessen fear of the natural world when these humans are off site, a "value added" of restoration ecology programming that should not be discounted. Sustainable living includes cognitive advances as well as conservation of resources and energy!
Ecoservices: The typical mission of restoration projects includes large areas that directly service wildlife, and other areas for human activity. This dichotomy is misleading, as functioning habitats for plants and wildlife offer much benefit for human populations, the extensively studied ecological services. These services would be hugely expensive to provide elsewhere, without natural habitat. Similarly, areas set aside for human behaviors can have much natural biodiversity, which both supports the sustainability of the broader landscape's biosphere and adds on-site pleasure to the humans, a notoriously curious species.

Some of the design and programming of public natural areas already focuses on the social and material needs of humans, the most important and influential species in most areas. However, the activities of humans profoundly affect all other species in adjacent areas, and determine, in large part, the ability of those species to persist regionally. Consequently, a primary focus of the restoration design process must appropriately be centered on humans.

A synthesis: On any visit to open space areas, one will encounter groups of humans engaged in a remarkable myriad of activities. Some people are active; others are resting or engaged in quiet, social communication activities. The display of widely varying human actions, and the individuals' extraordinary range of appearances and behaviors, gives to the viewer an infinitely changing experience. Despite the huge number of humans in the habitat, and the tremendous effort that managing these numbers will bring to management officials, landscape design actions must be directed at encouraging significant human presence there and the nurturing of human activities on most landscapes. This will subsequently build support for additional restoration ecology actions.

No matter how often visitors come to our project areas, observing and interacting with people will offer endless memorable moments. Human beings are a joy. 